\title{
Inclusive culture of kindergarten, school, college and university teachers
}

\author{
Olga Denisova ${ }^{1}{ }^{*}$, Olga Lekhanova $^{2}$, Valentina Ponikarova $^{3}$ and Tatyana Gudina ${ }^{3}$ \\ ${ }^{1}$ Department of special education, Director resource educational and methodical center, \\ Cherepovets State University, Cherepovets, Russia. \\ ${ }^{2}$ Resource educational and methodical center, Cherepovets State University, Cherepovets, \\ Russia \\ ${ }^{3}$ Cherepovets State University, Cherepovets, Russia
}

\begin{abstract}
Inclusive culture of teachers is one of the conditions for the successful inclusion of students with disabilities in the educational organization space. The authors identified 15 indicators characterizing the value, motivation and experience of teachers in the field of educational inclusion. Diagnostic results of inclusive culture of Vologda region are presented in the paper. The study shows that $63 \%$ of 1,100 teachers surveyed have a critical level of inclusive culture. As a result of the comparative analysis, it was determined that kindergarten and university teachers have a higher level of inclusive culture. In general, those teachers who have already had positive experience in social or educational inclusion are most interested in developing their competencies. The most active and highly motivated turned out to be those teachers who, in their personal experience, have had the opportunity to interact with the disabled and help people with disabilities to be included in society, education and life. Teachers with a developed inclusive culture, comprising $1 / 23$ of the 1,100 respondents surveyed, are characterized by the values and norms of inclusion, willingness to interact with the disabled, awareness of the necessity to acquire new knowledge and skills, social responsibility for the results of inclusion.
\end{abstract}

\section{Introduction}

Inclusion is one of the most discussed categories in Russian society, politics and science. One of the central definitions of the inclusion category is inclusive culture. In modern publications and in scientific discourse, the concept of inclusive culture is unambiguously associated with the tasks of developing an inclusive society, however, it is revealed and understood differently by various authors. The importance of studying the formation degree of the inclusive culture of Russian teachers is determined not only by the indisputable influence of education on the state of society's culture, but also by the need to study the cross-cultural specifics of the sociocultural attitude of Russian teachers as a key factor determining the success of inclusion.

\footnotetext{
*Corresponding author: denisova@inbox.ru
} 


\section{Background}

The problem of studying inclusive culture lies at the intersection of scientific disciplines and can only be successfully solved with an interdisciplinary approach to the issue. Without going into details of the culturological discussion, we point out that in philosophy, anthropology, and sociology it is determined that humanity can find itself only in culture [1]; culture is seen as a distinctive feature of a man [2]; it consists of internal and external norms of behavior [3], their internal experiences and external manifestations [4]; culture includes knowledge, beliefs, art, morality, laws, customs and some abilities and habits adopted by a person as a member of society [5] and forming this society [6]. A.Yu. Shemanov, N.T. Popova, A.S. Ekushevskaya, considering inclusion in a cultural perspective, focus on the special cultural needs of people with disabilities, pointing out the need to create a supportive sociocultural environment that promotes inclusion and integration of people with disabilities. [7]. The authors emphasize that the concept of inclusive culture in modern science is developed based on both the social model of disability and the socio-constructionist approach to culture [8]. V.N. Yarskaya and E.R. Yarskaya-Smirnova note that the achievement of equal opportunities for all is ensured by special mechanisms of social institutions of education, law, and also through the dissemination of values and norms, in accordance with which interaction and mutual understanding of people is built [9]. P.V. Romanov, V.V. Yakovleva analyze the mechanisms of corporate inclusive culture formation, which, according to the authors, is ensured by a set of measures, procedures, programs, rules and actions that create an environment where the diversity of human needs and values does not interfere, but contributes to success [10]. A description of such conditions for creating inclusion in the workplace, where special emphasis is placed on the willingness of employees to interact with each other and clients regardless of racial, cultural, national, gender differences or personal characteristics, is given in the Equality and Human Rights Commission Guidance [11].

In psychological and pedagogical research devoted to social and educational inclusion, attempts are made to identify and describe the component structure of inclusive culture. In the practical guide of T. Booth and M. Ainsko, inclusive culture is understood as the adoption of inclusive values, the implementation of inclusive policies and inclusive practices [12]. S.V. Alekhina, determining the need to transform the educational valuenotional field in the context of inclusive culture in educational organizations, points to such manifestations of inclusive culture as a willingness to "get involved" in the process of interaction with others, learning to be open to communication, seeing the need to be changed, being able to accept features and differences of other people [13] V.V. Khitryuk considers inclusive culture as an integrative personal quality that contributes to the creation and development of values and technologies of inclusive education and integrates a system of knowledge, skills, social, personal and professional competencies that allow a teacher to work effectively in inclusive education (integrated learning), determining the optimal development conditions for each child. According to the author, the formation of inclusive culture goes through a number of stages, with the first stage of inclusive readiness [14]. A.A. Sinyaevskaya identifies five components in inclusive culture structure: axiological (a system of inclusive values), ideological (personal focus on the implementation of inclusive ideas), personal (a set of personal qualities important for working in an inclusive environment), behavioral (specific etiquette standards specific to social interactions within an inclusive community), psychological (awareness of some psychic phenomena of inclusion) [15]. K.G. Bagdueva, I.A. Gadzhiev, F.G. Gadzhiev understand inclusive culture of an organization as a system of principles and values, including an external (educational space in accordance with the principles of accessibility and security; adapted educational 
programs) and internal (the system of views, rules, attitudes, values and behaviors common to the group) structure [16]. N.V. Starovoit, considering inclusive culture, offers an iceberg model. Highlighting the surface (features of the educational space, material and technical base, pedagogical technologies applied), underwater (values, beliefs, norms in educational process, beliefs shared by the members of the organization, standard procedures and modes of behavior) and deep (basic theoretical (fundamental) provisions of inclusive education) levels. [17]. E.L. Tikhomirova and E.V. Shadrova believe that inclusive culture of the educational organization as a component of the organizational culture should be separated from the inclusive culture of the individual subjects of the educational process (teachers, students, their parents, social partners) as their reflection and behavior [18]. Based on the idea of inclusive culture, the authors made a questionnaire that showed the need to form an inclusive community and inculcate inclusive values [19]. S.V. Alekhina and A.Yu. Shemanov also describe inclusive culture as an organizational culture that promotes both the successful implementation of the organization's goals and the creation of an inclusive environment - an inclusive community in which the basic assumptions of its participants contribute to the implementation of inclusion values (acceptance of diversity and participation) [20]. V.N. Ponikarova, studying the readiness of teachers for inclusive education, draws conclusions about the value, motivational and emotional attitude of teachers to inclusion, which is implemented through the typology of coping behavior in professional activity [21].

Thus, the analysis of the research works showed that inclusive culture is the fundamental basis for forming a culture of inclusive society in which the diversity of needs is welcomed, supported, accumulated by society, providing the opportunity to achieve high results in accordance with the goals of inclusive education and ensuring safety, acceptance, cooperation and stimulation of continuous improvement of the pedagogical community and society as a whole. The experience of defining and studying inclusive culture shows that the structure of the category under discussion includes two large components, the first of which relates to organizational conditions, the second to the culture of the organization's employees. The first component is clearly regulated in the legal field of the Russian Federation (Federal Law of December 29, 2012 No. 273-Ф3 "On Education in the Russian Federation", Decree of the President of the Russian Federation of May 5, 2012 No. 597 "On measures for the implementation of state social policy", the state program of the Russian Federation "Accessible Environment", etc.) and is the subject to monitoring assessment by the regulatory and supervisory authorities, but the second component of inclusive culture is considered mainly through the readiness of teachers for inclusive education. At the same time, the degree of inclusive culture formation is just entering scientific discourse and needs detailed discussion and study.

\section{Methods}

Taking into consideration the impact of education on the state of inclusive society, we have designed a methodology for assessing employees' inclusive culture. The methodology includes 15 questions in 4 semantic blocks: the values and norms of inclusion, willingness to interact in inclusion, awareness of the need for new knowledge and skills, social responsibility for the results of inclusion. Each respondent chose one of the answers for each question: yes, no doubt ( 5 b.), rather yes (4 b.), not ready to answer the question ( $3 \mathrm{~b}$.), rather no $(2 \mathrm{~b}$.), definitely not $(1 \mathrm{~b}$.). As a result of summing up the points, the level of formation of inclusive culture was determined: acceptable (high (61 - 75 points), advanced (56 - 60 points), sufficient (40 - 55 points)), unacceptable (critical (28 - 39 points), low (15 - 27 points)). Also, data for each of the components of inclusive culture were analyzed. 


\section{Results}

The study involved 1,100 teachers of all levels of education who work in the Vologda region institutions implementing inclusion. Table 1 shows the results of the study.

Table 1. The level of inclusive culture (IC) formation of Vologda region kindergarten, school, college and university teachers $(\%)$

\begin{tabular}{|l|l|l|c|c|c|r|}
\hline \multicolumn{2}{|l|}{ IC levels } & $\begin{array}{l}\text { Kinderga } \\
\text { rtens }\end{array}$ & $\begin{array}{l}\text { School } \\
\text { s }\end{array}$ & $\begin{array}{l}\text { Collleg } \\
\text { es }\end{array}$ & $\begin{array}{l}\text { Univer } \\
\text { sities }\end{array}$ & Total \\
\hline \multirow{3}{*}{ Acceptable } & High & 12,9 & 2,9 & 2,5 & 17,5 & 8,6 \\
\cline { 2 - 7 } & Advanced & 15,7 & 8,0 & 10,0 & 20,5 & 13,1 \\
\cline { 2 - 7 } & Sufficient & 28,6 & 2,9 & 1,5 & 5,0 & 11,2 \\
\hline \multirow{3}{*}{ Unacceptable } & Critical & 40,0 & 80,6 & 81,0 & 57,0 & 63,5 \\
\cline { 2 - 8 } & Low & 2,9 & 5,7 & 5,0 & 0,0 & 3,6 \\
\hline
\end{tabular}

High level of IC presupposes that the respondents unconditionally accept the values of inclusion, sincerely believe that each participant of educational relations benefits from it, are ready to interact in a wide social context, recognize and accept the need to change themselves personally and professionally and take responsibility for effectiveness of inclusion. Advanced level is manifested by the teacher who demonstrated a stable attitude towards the adoption and implementation of inclusion principles and values, who are ready to develop their professional competencies and to interact on inclusion with the society. Sufficient level is showed by the teachers who accept the values of inclusive education, who are aware of the need for additional knowledge and skills and are ready for communication with the main participants in inclusive educational relationships. Critical level is manifested by the teachers who understand the inevitability of the changes that take place, don't consider inclusion to be a resource for the development of society, don't realize or accept the value of individualization, are ready to interact on inclusion issues only in a narrow professional circle. Low level is characterized by a rejection of the values and norms of inclusion, a denial of the need to develop professionally important qualities and skills, and a lack of willingness to interact on inclusion.

As a result of the comparative analysis, it was determined that Vologda region kindergarten and university teachers demonstrate a higher level of inclusive culture. We believe that this is due to a number of factors: the traditions formed in the region, the experience of training specialists in preschool defectology and the functioning of the Northwestern Federal District Resource-Methodical Center for the education of people with disabilities on the basis of the Cherepovets State University. We associate lower indicators of inclusive culture in schools and secondary vocational education institutions with poor communication between correctional and secondary schools, with the priority of the value of mastering educational programs and a focus on final certification, as well as with a low level of professional readiness and little experience of teachers' work in inclusion.

In general, it was determined that acceptable level of inclusive culture is characteristic of $32.9 \%$ of the surveyed teachers. The application of the Spearman rank correlation criterion showed that, in general, most active and highly motivated are those teachers who have had a positive experience of social or educational inclusion, who in their personal experience or life have had the opportunity to interact with the disabled and help the inclusion of people with disabilities in the society, education and life, who are interested in developing their competencies $(r=0.77$, significant at $\rho \leq 0,05)$. 


\section{Conclusion}

Inclusive culture is the fundamental basis for the culture of inclusive society in which the diversity of needs is welcomed, supported, accumulated by society, providing the opportunity to achieve high results in accordance with the goals of inclusive education and ensuring the preservation, acceptance, cooperation and stimulation of continuous development of teachers and society as a whole. The components of employees' inclusive culture includes the adoption of the values and norms of inclusion, the willingness to interact in inclusion, awareness of the need for new knowledge and skills, social responsibility for the results of inclusion. Teachers of inclusive education in Vologda region represent groups that are heterogeneous in terms of inclusive culture. The highest level of inclusive culture is demonstrated by the kindergarten and university teachers who have positive experience in social and educational inclusion.

\section{References}

1. N.A. Berdyaev, CW, 4, (1990)

2. L. White Favorites, The Science of Culture (Russian Political Encyclopedia, Moscow, 2004)

3. Al. Kroeber, Cl. Kluckhohn, Culture: A Critical Review of Concepts and Definitions (Published by the Museum, Cambridge, 1952)

4. G.Devereux, The Making of Psychological Anthropology (University of California Press, California, 1980)

5. E.B. Taylor, The prehistoric life of mankind and the beginning of civilization, (Macmillan and Co, London, 1868)

6. M. Herskovits, Cultural Anthropology (Knopf, New York, 1955)

7. A.Yu.Shemanov, N.T. Popova, PSE, 1, 74-82, (2011)

8. A.Yu.Shemanov, A.S. Ekushevskaya, MFP, 7, 29-37, (2018)

9. V.N.Yarskaya, E.R. Yarskaya-Smirnova, SS, 12 (380), 133-140, (2015)

10. P.V. Romanov, V.V. Yakovleva, DJS, 1, 97-105, (2013)

11. URL:https://smarttar.co.uk/wpcontent/uploads/2015/12/an_employers_guide_to_c reating_a_diverse_workforce.pdf (2015)

12. T. Booth, M. Ainsko, Indicators of inclusion: practical guide (Russian Political Encyclopedia, Moscow, 2007)

13. S.V. Alekhina, PSE, 19. 1, 5-16 (2014)

14. V.V. Khitryu, BBSU, 1-1, 80-84, (2012)

15. A.A. Sinyavskaya, CAFGPCS, 72-78, (2017)

16. K.G. Bagdueva, I.A. Gadzhiev, F.G. Gadzhieva, WSCE, 1 (62), 111-112 (2017)

17. N.V. Starovoit, SMEJ, 8, 31-35 (2016)

18. E.L. Tikhomirova, E.V.Shadrova, PPRDMS, 93-98 (2017)

19. E. L. Tikhomirova, E. V. Shadrova, HSET, 8, 163-168 (2016)

20. S.V. Alekhina, A.Yu. Shemanov, 5-13 (2018)

21. V.N. Ponikarova The dynamics of teachers' readiness for inclusive education: stages, features and trends (University Book, Kursk, 2019) 